\title{
BEM- ESTAR NO CONTEXTO DE TRABALHO E NÃO-TRABALHO: UM ESTUDO CORRELACIONAL
}

\section{ARTIGO ORIGINAL}

FONTOURA, Aline da Silva ${ }^{1}$

FONTOURA, Aline da Silva. Bem- estar no contexto de trabalho e não-trabalho: um estudo correlacional. Revista Científica Multidisciplinar Núcleo do Conhecimento. Ano. 07, Ed. 01, Vol. 06, pp. 16-36. Janeiro de 2022. ISSN: 2448-0959, Link de acesso: https://www.nucleodoconhecimento.com.br/psicologia/ bem-estar

\section{RESUMO}

O trabalho faz parte da história e do movimento de mudanças da sociedade. Estudar o bem-estar no trabalho se faz necessário para acompanhar as constantes mudanças na estrutura social e compreender o impacto das atividades laborais na percepção de bem-estar no contexto de trabalho e de não trabalho dos indivíduos que vivem a dinâmica contemporânea de estreitamento da "barreira" profissional-pessoal. Questão problema: A presente pesquisa discute o grau de relação entre satisfação no trabalho, comprometimento organizacional afetivo, envolvimento no trabalho e bem-estar no trabalho, contextualizando o panorama de diminuição da dicotomia "vida" profissional e pessoal na sociedade na atualidade, em outras palavras, o estudo busca responder qual é o grau de correlação das variáveis do bem-estar no trabalho com a percepção de bem-estar no contexto de não-trabalho(bem-estar subjetivo), ou seja, com o bemestar geral. Objetivo: analisar o bem-estar no contexto do trabalho a partir de seu caráter superordenado, composto pelas variáveis: satisfação no trabalho, envolvimento no trabalho e comprometimento organizacional afetivo; e o bem-estar no contexto de não-trabalho (bem-estar subjetivo) através da variável felicidade subjetiva. Metodologia: $O$ estudo contou com a participação de 457 trabalhadores que

${ }^{1}$ Graduada em Psicologia. ORCID: 0000-0003-1735-5898

RC: 105620

Disponível em: https://www.nucleodoconhecimento.com.br/psicologia/bem-estar 
também eram estudantes universitários de uma instituição privada com abrangência nacional, que responderam a Escala de Envolvimento com o Trabalho, a Escala de Satisfação com o trabalho, a Escala de comprometimento organizacional afetivo e a Escala de felicidade subjetiva, além do Questionário de dados sociodemográficos. Os dados foram analisados por meio um estudo correlacional e demonstraram que as variáveis possuem grau de correlação entre si. Principais resultados e conclusões: Conclui-se que todas as variáveis tiveram correlações, sendo envolvimento no trabalho e satisfação no trabalho com o resultado mais fraco $(0,193)$ comparado aos outros, mas ainda considerável. Isso sugere que é possível que alguns trabalhadores estejam envolvidos no trabalho ainda que não tão satisfeitos com ele. A satisfação no trabalho com a felicidade subjetiva foram as variáveis que expressaram maior correlação $(0,552)$, dessa forma é possível considerar que o nível de satisfação do trabalho tem estreita relação com o bem-estar no contexto de não-trabalho (bem-estar subjetivo).

Palavras-Chave: Bem-estar no trabalho, Satisfação no Trabalho, Engajamento no Trabalho, Comprometimento Organizacional afetivo.

\section{INTRODUÇÃO}

De acordo com Pais-Ribeiro (2012) os estudos sobre felicidade atraem olhares de estudiosos, como os filósofos Democritus, Sócrates, Platão e Aristóteles desde a antiguidade. Todavia, enquanto os filósofos debatem a essência do estado de felicidade, ou seja, o que é felicidade, sua ontologia; nas últimas três décadas, pesquisadores empenharam-se em descobrir o quanto as pessoas se consideram felizes ou em que medida são capazes de realizar plenamente suas potencialidades. $\mathrm{Na}$ declaração de independência dos Estados Unidos no século XVIII já aparece o conceito de felicidade. Contudo, na constituição da República Portuguesa, ao invés desse termo, o que se observa são as expressões "bem-estar" e "qualidade de vida".

Semelhantemente, o trabalho não só faz parte da história, mas também, da estrutura da sociedade, a ponto de suas transmutações estarem diretamente ligadas. Isto é, a RC: 105620

Disponível em: https://www.nucleodoconhecimento.com.br/psicologia/bem-estar 
dinâmica social se dá de forma diferente nos períodos do artesão, do operário e do trabalhador contemporâneo. E para acompanhar as diversas mudanças sociais, as organizações cada vez mais têm dirigido a atenção para a força de trabalho como foco estratégico na competição com concorrentes (COVACS, 2006).

É indiscutível a importância de estudos sobre o bem-estar no trabalho, porém tanto os modelos teóricos, como também, os empíricos sobre o fenômeno são escassos. Há na literatura da psicologia organizacional um número significativo de estudos sobre qualidade de vida e estresse no trabalho, que representam conceitos relacionados ao bem-estar. Todavia, as análises específicas do construto do bem-estar no trabalho são poucas, haja vista que o bem-estar geral, desassociado de qualquer contexto, consiste no foco das principais investigações.

Por fim, nestes comentários iniciais, foi realizada uma breve análise acerca do momento atual das organizações ante as possibilidades humanas, pois o objetivo do estudo é analisar o bem-estar no contexto do trabalho a partir de seu caráter superordenado, composto pelas variáveis: satisfação no trabalho, envolvimento no trabalho e comprometimento organizacional afetivo; e o bem-estar no contexto de nãotrabalho (bem-estar subjetivo) através da variável felicidade subjetiva. A partir desta pesquisa discute-se como problemática o grau de relação entre satisfação no trabalho, comprometimento organizacional afetivo, envolvimento no trabalho e bem-estar no trabalho, contextualizando o panorama de diminuição da dicotomia "vida" profissional e pessoal na sociedade na atualidade, em outras palavras, o estudo busca responder qual é o grau de correlação das variáveis do bem-estar no trabalho com a percepção de bem-estar no contexto de não-trabalho (bem-estar subjetivo).

A relevância deste estudo advém da necessidade de pesquisas que contribuam para assistência aos trabalhadores no que diz respeito ao bem-estar do indivíduo no trabalho (entendendo como fundamental para o bem-estar-geral). Observando-os de maneira mais humanizada e menos como capital humano. 


\title{
2. FUNDAMENTAÇÃO TEÓRICA
}

\subsection{BEM- ESTAR NO TRABALHO}

Fernandes et al. (2007) ao pesquisarem o Bem-estar no trabalho e a predição da exaustão emocional afirmam que o bem-estar no trabalho contém tanto uma dimensão cognitiva, avaliada pela satisfação no trabalho, como uma afetiva, associada aos afetos positivos e negativos dirigidos ao trabalho.

Siqueira e Padovam (2008), explicam que há uma multiplicidade de perspectivas sobre a compreensão de bem-estar no trabalho (BET), essas diferentes visões tratam tanto de temas positivos como satisfação com o trabalho, como também de negativos, como síndrome de burnout ou estresse. Fazendo uma trajetória a partir dos conceitos de bem-estar subjetivo e psicológico, as autoras propuseram o conceito de bem-estar no trabalho.

\begin{abstract}
Ainda não existem na literatura concepções claras sobre o conceito de bem-estar no trabalho. Quando tratam do assunto, os pesquisadores escolhem conceitos diversos para representá-lo, quer seja um fator positivo como satisfação com o trabalho (Amaral \& Siqueira, 2004) quer seja conceitos negativos como burnout (Maslach, Schaufeli \& Leiter, 2001) ou estresse (Byrne, 1994). Ademais, bem-estar e saúde são abordados de forma interdependente, especialmente quando os pesquisadores apontam fatores que possam comprometer ambos, tais como perigos do ambiente de trabalho, fatores de personalidade e estresse ocupacional (Danna \& Griffi, 1999) ou, ainda, segurança no trabalho, horas trabalhadas, controle do trabalho e estilo gerencial. (SIQUEIRA; PADOVAM, 2008, p. 205-206).
\end{abstract}

Fernandes et al. (2007, p. 3) entendem que "o bem-estar no trabalho pode ser considerado um construto superordenado, composto de uma dimensão cognitiva, associada à satisfação no trabalho, e de uma dimensão afetiva, manifesta em afetos positivos e negativos dirigidos ao trabalho".

Tais pesquisadores enfatizam duas abordagens para a compreensão do bem-estar no trabalho: a hedônica (aspectos afetivos) e a eudamônica (aspecto cognitivo/realização), onde ambas incluem tanto os aspectos afetivos, quanto

RC: 105620

Disponível em: https://www.nucleodoconhecimento.com.br/psicologia/bem-estar 
cognitivos. Ressaltam ainda que operacionalmente o bem-estar no trabalho é composto por três fatores: afeto positivo, afeto negativo e realização pessoal no trabalho.

O bem-estar no trabalho, deste modo, inclui tantos aspectos afetivos (emoções e humores), quanto cognitivos (percepção de realização) e engloba os pontos centrais da abordagem hedonista e da eudemonista. Em termos operacionais, o bem-estar no trabalho pode ser organizado em torno de três fatores: afeto positivo, afeto negativo e realização pessoal no trabalho. Os dois primeiros referem-se aos elementos hedônicos do bem-estar no trabalho e o último refere-se aos eudaimônicos. (PASCHOAL; PORTO; TORRES, 2010, p. 1058)

Destaca-se que enquanto o afeto positivo combina prazer, entusiasmo e conforto; o afeto negativo caracteriza-se por desprazer, ansiedade e depressão. (PASCHOAL; TORRES; PORTO, 2010).

Apesar da pluralidade do termo, observa-se que há um consenso em reconhecer bemestar como um conceito amplo, multifacetado e com certa estabilidade ao longo do tempo. Assim como Paschoal; Torres e Porto (2010) e Siqueira e Padovam (2008) consideram bem-estar no trabalho como um conceito dotado de três componentes que não são o afeto positivo, o afeto negativo e a realização pessoal no trabalho, são: satisfação com o trabalho, envolvimento com o trabalho e comprometimento organizacional.

[...] como se pode reconhecer, os três componentes do modelo teórico constitutivo de bem-estar no trabalho foram escolhidos porque cada um contempla aspectos psicológicos de natureza cognitiva (mental), nos quais estão inseridos crenças e sentimentos estritamente positivos e que emergem no contexto organizacional de trabalho. (SIQUEIRA Org., 2014, p. 40)

No presente estudo, o bem-estar no trabalho foi considerado a partir desses três componentes: envolvimento no trabalho, satisfação no trabalho e comprometimento afetivo organizacional. 


\subsection{ENVOLVIMENTO NO TRABALHO}

Acompanhando os estudos sobre o bem-estar no trabalho, o envolvimento com o trabalho (ENT) também vem tomando proporções mais significativas na área de gestão de pessoas, uma vez que pode ser visto como importante indicador da motivação dos trabalhadores no contexto organizacional.

Trabalhos contemporâneos de Muchinsky (2004) e Csikszentmihalyi (2004) apresentam o ENT sob duas óticas convergentes. Muchinsky (2004) descreve o envolvimento no trabalho não apenas fundamentado na importância da percepção de uma autoimagem, mas também, como o grau de identificação psicológica da pessoa com seu trabalho. Complementando essa definição, Csikszentmihalyi (2004) apresenta o envolvimento no trabalho como fluxo (flow) no qual a tarefa executada é capaz de absorver e manter o trabalhador imerso em sua realização. Levando em consideração o domínio pleno da função como fator capaz de elevar o nível de concentração do indivíduo, o autor enfatiza que o denominado fluxo ocorre quando as atividades do trabalho exigem habilidades especiais, cujas metas e feedback são claros e imediatos, mas ainda possibilita a realização da tarefa na fronteira entre o domínio e o desafio.

A perspectiva da Psicologia Positiva segue o caminho dos estudos de Csikszentmihalyi (2004) considerando o ENT como a capacidade que o trabalho tem de envolver o trabalhador (BASTOS et al., 2013). O flow se apresenta como um estado viável quando o indivíduo está envolvido na tarefa a ponto de harmonizar pensamento, sentimento e desejo, fazendo desaparecer a noção de tempo.

O conceito de envolvimento no trabalho pode ser interpretado a partir das concepções de Siqueira, cujo grau em que o trabalho consegue ser importante e envolver o trabalhador é visto como a essência do ENT. É possível compreender envolvimento com o trabalho mais contemporaneamente como um estado de completa absorção e assimilação pelo trabalho. Para compreensão dessa abordagem faz-se necessário entender o que significa estado de fluxo. (SIQUEIRA, 2008, p. 141)

RC: 105620

Disponível em: https://www.nucleodoconhecimento.com.br/psicologia/bem-estar 
Csikszentmihalyi (2004) apresenta o envolvimento no trabalho como fluxo (flow) no qual a tarefa executada é capaz de absorver e manter o trabalhador imerso em sua realização. Leva em consideração o domínio pleno da função como fator capaz de elevar o nível de concentração do indivíduo.

Um pouco mais tarde, ainda em conformidade com a ideia anterior, Siqueira e Gomide (2014) tomam o envolvimento com o trabalho como um construto do bem-estar no trabalho considerando o envolvimento com o trabalho o grau em que o desempenho de uma pessoa no trabalho afeta a sua autoestima.

Cavalcante; Siqueira e Kuniyoshi (2014, p. 56) afirmam: na medida em que um trabalhador relata otimismo, resiliência, esperança e eficácia (capital psicológico) ele tende a revelar vigor e absorção no ambiente de trabalho (engajamento no trabalho). Além disso,

[...] um indivíduo com elevados índices de bem-estar no trabalho tende também a manter um forte engajamento no trabalho e vice-versa. Desta forma, pode-se afirmar que na medida em que o engajamento no trabalho assumir valores altos crescem proporcionalmente nos profissionais pesquisados os indicadores de bem-estar no trabalho (satisfação, envolvimento e comprometimento organizacional) e viceversa. (CAVALCANTE; SIQUEIRA; KUNIYOSHI, 2014, p. 57)

O investimento de tempo e energia por parte do indivíduo pode ser considerado um aspecto característico de um indivíduo envolvido e comprometido com organização, apresentando ainda, sinais de vigor e maior facilidade de aprendizagem. Isso é possível quando o trabalhador percebe o significado da atividade para si mesmo, bem como, sua capacidade em realizá-la.

Tomaremos como base para este trabalho a perspectiva de Siqueira e Gomide (2014) tomando o envolvimento no trabalho como construto do bem-estar no trabalho, no qual o envolvimento no trabalho é considerado como o grau em que o próprio trabalho consegue ser importante e envolvente para o trabalhador. 


\subsection{SATISFAÇÃO NO TRABALHO}

Satisfação com a vida e no trabalho são construtos complexos. Uma parte dessa complexidade decorre da dificuldade de estabelecer uma definição de satisfação, haja visto que essa se configura como um estado subjetivo, isto é, variável de pessoa para pessoa mesmo que em uma mesma situação ou evento, também dispõe de natureza múltipla de circunstância para circunstância, e influências de forças internas e externas ao ambiente socio - histórico-cultural.

A satisfação com a vida, segundo Scorsolini-Comin e Santos (2010), é um construto que se refere à avaliação cognitiva que o indivíduo faz sobre sua qualidade de vida geral ou relativa a domínios como trabalho, saúde, lazer e relacionamento. Vale ressaltar que essa avaliação segue critérios próprios, ou seja, um padrão escolhido pelo indivíduo moldado a partir da comparação entre as circunstâncias de vida que o próprio indivíduo determinou para si.

Já o que diz respeito ao estudo da satisfação no ambiente laboral Siqueira (2008) aponta o fato da satisfação e da motivação no trabalho aparecerem juntas nas primeiras pesquisas devido o interesse em compreender os sentimentos que afetam os trabalhadores, ainda sim, é possível verificar vertentes diferentes de estudo. A mensuração dos níveis de satisfação dos trabalhadores como estratégia para medir a capacidade de promoção de saúde e bem-estar promovida pelas organizações aos seus colaboradores, por exemplo, tem natureza nos pressupostos humanistas e sociais.

Há um afastamento do olhar que produz o entendimento da satisfação como um fator com capacidade de predizer comportamentos de trabalho tais como produtividade, desempenho, rotatividade e absenteísmo em contrapartida uma aproximação da percepção do relacionamento intrínseco da relação do trabalho, da vida pessoal, familiar e social do indivíduo com suas condições de bem-estar e até sua saúde física e mental. A título de exemplo, para Leal $(2008$, p. 39): o que satisfaz o trabalhador é 
descobrir o procedimento que deve ser adotado em relação a ele para que melhore seu desempenho profissional.

Vale salientar que a expressão "satisfação no trabalho" representa a totalização do quanto o indivíduo que trabalha vivência experiências prazerosas no contexto das organizações. Isto posto, cada uma das dimensões de satisfação no trabalho compreende um fator ou uma fonte de tais experiências agradáveis (SIQUEIRA, 2008). Sendo assim, a satisfação no trabalho também pode ser estudada a partir da perspectiva de um estado emocional prazeroso oriundo da avaliação que o indivíduo faz de seu trabalho, ao mesmo tempo em que é resultado da percepção da pessoa sobre como este satisfaz ou permite satisfação de seus valores.

Martinez e Paraguay (2003), corroboram com a ideia acima, ao explicarem que há tanto um componente cognitivo, como também, um componente afetivo na concepção de satisfação no trabalho. No qual o componente cognitivo diz respeito ao que o indivíduo pensa e a suas opiniões sobre o trabalho, enquanto o componente afetivo diz respeito a quão bem uma pessoa se sente em relação a um trabalho. Tal arranjo sugere que a satisfação no trabalho é baseada parcialmente no que o indivíduo pensa e parte no que o indivíduo sente, se configurando como um sentimento experienciado pelo trabalhador em resposta à situação total do trabalho.

Apesar das transformações em sua concepção, na atualidade, a satisfação é apontada como um conceito que engloba afetividade e seus aspectos construtivos não sofreram alterações significativas. Em outras palavras, nos primórdios de sua concepção diversos estudiosos entendiam a satisfação no trabalho como um conceito integrado por várias dimensões. Contudo, os fatores que se mantém são cinco: satisfação com o salário, com os colegas de trabalho, com a chefia, com as promoções e com o próprio trabalho.

Apesar de transpor mais de 80 anos de sua existência sofrendo mutações em sua concepção, ora entendida como um aspecto motivacional, ora compreendida como atitude e, contemporaneamente, sendo apontada como um conceito que abarca

RC: 105620

Disponível em: https://www.nucleodoconhecimento.com.br/psicologia/bem-estar 
afetividade, satisfação no trabalho não sofreu grandes alterações em suas dimensões constitutivas. Desde os primeiros anos de sua concepção já existiam proposições, defendidas por diversos estudiosos (Herzberg, Mausner \& Snyderman, 1959; Smith, Kendall \& Hulin, 1969) de ser satisfação no trabalho um conceito integrado por várias dimensões. As que conseguiram manter se ao longo de décadas foram cinco: satisfação com o salário, com os colegas de trabalho, com a chefia, com as promoções e com o próprio trabalho (SIQUEIRA, 2008, p. 267).

Com fundamento na Teoria de Locke sobre Satisfação no Trabalho as pesquisadoras Martinez e Paraguay (2003) identificam e categorizam os fatores causais da satisfação no trabalho relacionados ao ambiente de trabalho como eventos, condições e agentes. Cujos eventos e condições são: o trabalho, o pagamento, a promoção, o reconhecimento e as condições/ambientes de trabalho; e os agentes são: colegas e subordinados, a supervisão e gerenciamento; e a empresa/organização.

Vale destacar a compreensão de satisfação no trabalho como um resultado do ambiente organizacional sobre a saúde do trabalhador. Identificando- a como um dos três componentes psicossociais do conceito de bem-estar no trabalho, junto ao envolvimento no trabalho e comprometimento organizacional afetivo. (PADOVAM; SIQUEIRA, 2008)

\subsection{COMPROMETIMENTO ORGANIZACIONAL AFETIVO}

Pesquisas que abordam o comprometimento no trabalho fazem parte dos interesses compartilhados no campo organizacional, pois se configuram como ferramentas de mensuração importantes na compreensão desse meio. Através dos estudos sobre bom desempenho, eficiência e eficácia, além das relações interpessoais. Tais estudos são pertinentes para olhar a dinâmica do vínculo dos trabalhadores com suas organizações e como tal ligação influencia o desempenho do indivíduo no trabalho (ROWE; BASTOS,2009).

Rowe e Bastos (2009) apresentam o modelo tridimensional proposto inicialmente por Meyer e Allen (1991) formado por três bases conceituais do comprometimento:

RC: 105620

Disponível em: https://www.nucleodoconhecimento.com.br/psicologia/bem-estar 
afetiva; normativa e instrumental ou calculativo. Definem também cada uma das três bases do comprometimento. $\mathrm{Na}$ qual a base afetiva refere-se: ao comprometimento que resulta de um vínculo afetivo em relação à organização, com o sujeito identificando-se e envolvendo-se com ela. Nessa situação, o trabalhador permanece na organização porque quer. (ROWE; BASTOS, 2009, p. 2)

Enquanto a normativa se configura a partir de um sentimento de dever, por vezes, carregado também de desconforto e dúvidas quanto ao fato de continuar na empresa.

Quando o comprometimento reflete um sentimento de obrigação do sujeito em permanecer na organização. Este vínculo constitui-se em um conjunto de pensamentos no qual são reconhecidos obrigações e deveres morais para com a organização, que são acompanhados ou revestidos de sentimentos de culpa, incômodo, apreensão e preocupação quando o trabalhador pensa ou planeja se desligar da mesma. (ROWE; BASTOS, 2009, p. 2)

A base instrumental diz respeito: ao comprometimento que decorre do reconhecimento dos custos em deixar a organização (ROWE; BASTOS, 2009, p. 2). Em outras palavras, o trabalhador mantém o vínculo empregatício, pois é necessário.

Bastos e Rodrigues (2010) se debruçaram sobre o estudo dos problemas desse modelo tridimensional do comprometimento, para então expor ajustes que levam em consideração a multiplicidade da temática. A partir do mapeamento das definições de comprometimento organizacional, eles agrupam os dados em dois tipos básicos de vínculos: o ativo e o passivo.

[...] há uma grande amplitude de facetas incorporadas ao conceito de comprometimento. Há, ainda, uma clara separação entre dimensões que representam um vínculo ativo, expresso pelo engajamento, intenção de empenho extra, afeto e identificação com a organização e as dimensões que manifestam uma relação passiva, que se resume à permanência e à relação de troca com a organização, onde se enquadra o vínculo instrumental de continuação. Algumas definições de comprometimento formaram a categoria "obrigação", posicionada no mapa de forma central, uma vez que o indivíduo pode se sentir em obrigação com a organização em função de um vínculo afetivo (ativo), ou se sentir obrigado a cumprir certos procedimentos e regras de

RC: 105620

Disponível em: https://www.nucleodoconhecimento.com.br/psicologia/bem-estar 
trabalho como forma de manter o emprego ou status alcançado (passivo). (BASTOS; RODRIGUES, 2010, p. 133)

No mesmo ano Bastos e Ribeiro publicam um estudo no qual apresentam o comprometimento como fator fundamental para um relacionamento interpessoal coeso, de modo que se movimentam a atingir os resultados esperados.

[...] o comprometimento é uma das forças relevantes que compõe a vitalidade competitiva da organização [...] é o atributo único e exclusivo de uma equipe de determinada organização que não pode ser clonado por outros competidores e que propicia constância e vigor ao seu ânimo competitivo [...] e é por isso que todas as empresas aspiram ter empregados comprometidos com seus valores, crenças, estratégias e resultados. (BASTOS; RIBEIRO, 2010, p. 6).

As pesquisadoras Traldi e Demo (2012) em convergência com estudos anteriores tomam o comprometimento no trabalho como um construto advindo de contratos psicológicos entre organização e colaboradores. Elas declaram que um melhor entendimento do comprometimento organizacional é viável quando as análises levam em consideração as múltiplas bases e focos do construto.

Siqueira (2008) expõe quatro bases do comprometimento, o comprometimento atitudinal/afetivo, o comprometimento instrumental, o comprometimento normativo e o comprometimento comportamental.

Martins; Costa e Siqueira (2015) observam que o comprometimento organizacional está intimamente relacionado com o envolvimento no trabalho no estudo sobre os comportamentos de cidadania organizacional.

é perceptível uma sobreposição conceitual entre os diversos modelos propostos para demarcar o campo semântico do comprometimento organizacional.

O presente trabalho será orientado a partir das pesquisas de Medeiros et al. (2003) nas quais a validação do modelo para as bases do comprometimento organizacional levou em consideração o contexto cultural brasileiro, cuja dimensão afetiva é definida como a internalização dos valores e objetivos organizacionais.

RC: 105620

Disponível em: https://www.nucleodoconhecimento.com.br/psicologia/bem-estar 


\subsection{FELICIDADE SUBJETIVA/BEM-ESTAR SUBJETIVO}

Lyubomirsky e Lepper (1999) estudam a felicidade subjetiva com fundamento em sua validação como indicador de bem-estar subjetivo. Segundo Pais-Ribeiro (2012), a visão sobre a ontologia de felicidade passou por transmutações. Visto que inicialmente o filósofo Democritus tomava a felicidade como indicador de uma vida feliz construída, percebida a partir da reação do indivíduo às circunstâncias de seu cotidiano. A posteriori, com a concepção eudemônica de felicidade tal perspectiva foi colocada de lado.

Para Diener e Lucas (2000) os autorrelatos de felicidade possuem, em sua maioria, evidências de consistência interna significativas. Ou seja, é necessário considerar a avaliação de cada indivíduo sobre sua vida como importante indicador de tal construto no mesmo.

Keyes; Shimotkin e Ryff (2002) entendem que a composição emocional do conceito de Bem-estar subjetivo inclui uma dinâmica entre afetos positivos e afetos negativos. Como em um jogo de forças, para que haja o bem-estar subjetivo, é necessária uma relação positiva entre os afetos, ou seja, a percepção de mais afetos positivos do que negativos. Visto isso, esta dimensão de bem-estar subjetivo guarda forte relação com a visão hedônica de felicidade, na medida em que dá ênfase aos aspectos afetivos da vida.

É possível notar uma convergência dos estudos de Diener e Lucas (2000) e Keyes; Shimotkin e Ryff (2002) na pesquisa nacional de Pais-Ribeiro (2012) de validação transcultural da escala de felicidade subjetiva de Lyubomirsky e Lepper, onde a satisfação com a vida (dimensão cognitiva) e a presença de afeto positivo e ausência de afeto negativo (dimensão afetiva) são apresentadas como variáveis de bem-estar subjetivo.

O que se percebe é que ao longo dos anos há um interesse cada vez maior pelo tema da felicidade. No entanto, ainda é difícil definir na literatura um consenso sobre a RC: 105620

Disponível em: https://www.nucleodoconhecimento.com.br/psicologia/bem-estar 
questão, sendo possível dizer que se trata de assunto complexo e que muitas vezes se aborda o bem-estar. Vale ressaltar também a escassez de pesquisas nacionais sobre esse construto em comparação com os demais discutidos anteriormente.

\subsection{BEM- ESTAR PSICOLÓGICO}

Araújo e Oliveira (2008) amparam seus estudos sobre o bem-estar psicológico (BEP) adotando a visão de felicidade, e consequentemente de bem-estar, centrada na experiência de expressividade pessoal e de autorrealização. Em outras palavras, o conceito de bem-estar psicológico é organizado por compreensões de cunho psicológico sobre o desenvolvimento humano e suas capacidades em resolver as adversidades cotidianas.

[...] enquanto bem-estar subjetivo está permeado por avaliações da satisfação com a vida e os afetos positivos e negativos que revelam a felicidade, bem-estar psicológico é consistentemente estruturado por formulações psicológicas sobre o desenvolvimento humano e suas capacidades em enfrentar os desafios da vida (ARAÚJO; OLIVEIRA, 2008, p. 11).

Keyes e Ryff (1995) estudaram o BEP levando em consideração a complexidade de sua multiplicidade de dimensões, organizando-as em seis: autonomia; autoaceitação; crescimento pessoal; propósito de vida; relacionamento positivo com outras pessoas e domínio do ambiente. Os índices dessas dimensões são capazes de mensurar o grau de bem-estar psicológico de um indivíduo de maneira empírica.

Vale ressaltar, que a principal diferença entre a concepção de bem-estar subjetivo e bem-estar psicológico é a maneira que se entende a felicidade. Haja visto que enquanto o bem-estar subjetivo se ampara, tipicamente em avaliações de satisfação com a vida e num balanço entre afetos positivos e negativos; as concepções dos especialistas que se implicaram nos estudos do bem estar psicológico apresentam as formulações psicológicas acerca do desenvolvimento humano não apenas a capacidades para enfrentar os desafios da vida.

RC: 105620

Disponível em: https://www.nucleodoconhecimento.com.br/psicologia/bem-estar 
A partir de Siqueira e Padovam (2008) é possível distinguir dois componentes do bemestar: o objetivo e o subjetivo, onde o primeiro é identificado por padrões de vida, enquanto o segundo está relacionado ao estado psicológico do indivíduo.

\section{MÉTODO}

\subsection{PARTICIPANTES}

Participaram do estudo 457 trabalhadores que também eram estudantes universitários de uma instituição privada com abrangência nacional. Destes 153 (33,5\%) eram do sexo masculino e $304(66,5 \%)$ do sexo feminino, com idade variando de 18 a 58 anos (média de 28,19 anos; desvio padrão de 7,623 anos). Duzentos e quarenta e cinco indivíduos $(53,6 \%)$ eram solteiros, cento e noventa e um indivíduos $(41,8 \%)$ eram casados. Vinte e um indivíduos $(4,6 \%)$ se identificaram como "outro". Os participantes eram oriundos de diferentes estados brasileiros das cinco regiões do Brasil (Norte, Nordeste, Centro-Oeste, Sul e Sudeste).

\subsection{INSTRUMENTOS}

Para mensuração do envolvimento no trabalho foi utilizada a Escala de Envolvimento com o Trabalho - EET, construída e validada por Lodahl e Kejner (1965), e adaptada por Siqueira (1995). Ela contém cinco questões sobre envolvimento com o trabalho e os elementos abordados são: (i) as maiores satisfações da minha vida vêm de meu trabalho; (ii) as horas que passo trabalhando são as melhores horas de meu dia; (iii) as coisas mais importantes que acontecem em minha vida envolvem o meu trabalho; (iv) eu como, vivo e respeito o meu trabalho, e (v) eu estou pessoalmente muito ligado ao meu trabalho.

A Satisfação no trabalho foi mensurada com a versão em português da Job Satisfaction Scale (Escala de Satisfação com o trabalho) desenvolvida por Judge e Klinger (2000). A escala é composta por cinco itens, sendo que cada um foi avaliado em uma escala de cinco níveis ( 1 = Nunca; 2 = Algumas Vezes; 3 = Regularmente; 4

RC: 105620

Disponível em: https://www.nucleodoconhecimento.com.br/psicologia/bem-estar 
= Bastantes Vezes; 5 = Sempre). Judge e Klinger reportaram um Coeficiente de Alfa de Cronbach de 0,80 no estudo original.

Para mensuração do Comprometimento Organizacional Afetivo foi utilizada a ECOA - Escala de comprometimento organizacional afetivo - que se refere ao afeto nutrido pelo trabalhador pela empresa. Foi utilizada a sua versão reduzida de Siqueira (1995), que possui 5 expressões de afetos dirigidos à empresa, onde o trabalhador deve indicar numa escala tipo Likert de cinco pontos, correspondendo a: 1 nada; 2 poucos; 3 mais ou menos; 4 muito; 5 extremamente, a intensidade com que sente estes afetos.

Para mensuração da Felicidade subjetiva foi utilizada a Escala de felicidade subjetiva - desenvolvida por Lyubomirsky e Lepper (1999) - que inclui quatro itens, que são afirmações em que, em duas, se pede aos respondentes para se caracterizarem a si próprios por comparação com os seus pares, quer em termos absolutos, quer relativos (itens dois e três). Os outros dois itens consistem em descrições de felicidade e infelicidade. Pede-se aos respondentes para indicar a extensão em que as afirmações os caracterizam. A resposta é dada numa escala análoga visual com sete posições, ancorada em duas afirmações antagônicas que expressam o nível de felicidade ou a sua falta.

O questionário de dados sociodemográficos foi estruturado com informações sobre idade, sexo, estado civil, se o indivíduo tinha filhos, renda mensal familiar, escolaridade da mãe e do pai, curso e número da matrícula na universidade (opcional).

\subsection{PROCEDIMENTOS}

Os instrumentos do estudo foram disponibilizados aos participantes através da plataforma Survey Monkey, durante o primeiro semestre do ano de 2018. O Termo de Consentimento Livre e Esclarecido (TCLE) foi disponibilizado, bastando clicar em "eu aceito" para iniciar o preenchimento do questionário de pesquisa. 


\section{RESULTADO E DISCUSSÃO}

Antes de iniciar a análise dos dados do estudo, foi realizada uma análise fatorial confirmatória de cada instrumento, buscando verificar se eles possuíam características psicométricas que os recomendavam para a realização da investigação com os participantes deste estudo.

Após verificação dos pressupostos para as análises, foram realizadas correlações entre todos os fatores pesquisados, conforme a Tabela 1 e a Tabela 2.

Tabela 1: Análise descritiva das variáveis do estudo

\begin{tabular}{|l|l|l|l|}
\hline Variáveis & Média & Mediana & Desvio padrão \\
\hline 1. Envolvimento no Trabalho & 2,8425 & 2,8000 & 0,78798 \\
\hline 2. Satisfação no Trabalho & 3,6276 & 3,8000 & 0,76390 \\
\hline 3. Comprometimento Organizacional Afetivo & 3,3527 & 3,4000 & 0,95543 \\
\hline 4. Felicidade subjetiva & 5,1320 & 5,3333 & 1,23794 \\
\hline
\end{tabular}

Fonte: Elaborada pela autora.

Tabela 2: Análise correlacional das variáveis do estudo

\begin{tabular}{|c|c|c|c|c|}
\hline Variáveis & 1 & 2 & 3 & 4 \\
\hline 1. Envolvimento no Trabalho & - & $0,193^{\star *}$ & $0,504^{\star *}$ & $0,214^{\star *}$ \\
\hline 2. Satisfação no Trabalho & $0,193^{\star *}$ & - & $0,247^{\star \star}$ & $0,552^{* \star}$ \\
\hline 3. Comprometimento Organizacional Afetivo & $0,504^{* *}$ & $0,247^{* *}$ & - & $0,287^{* *}$ \\
\hline 4. Felicidade subjetiva & $0,214^{* *}$ & $0,552^{* *}$ & $0,287^{* *}$ & - \\
\hline
\end{tabular}

Nota. ${ }^{* *}$ Significativo ao nível de 0,01. Fonte: Elaborada pela autora.

Os dados demonstraram que as variáveis possuem correlação entre si. Conforme as pesquisas de Paschoal; Torres e Porto (2010) e Padovam e Siqueira (2008) que compreendiam a satisfação no trabalho, o envolvimento no trabalho e o

RC: 105620

Disponível em: https://www.nucleodoconhecimento.com.br/psicologia/bem-estar 
comprometimento organizacional como constructos que compõem o bem-estar no trabalho. Distanciando-se das teorias que propunham o bem-estar no trabalho como conjunto dos afetos positivos, dos afetos negativos e da realização pessoal no trabalho.

O comprometimento organizacional afetivo apresentou correlação positiva e de moderada a alta com envolvimento no trabalho $(0,504)$. De acordo com os estudos de Siqueira e Gomide (2014) uma característica de pessoas envolvidas e comprometidas em suas atividades laborais é o investimento de tempo e energia por parte desses indivíduos.

A satisfação no trabalho com a felicidade subjetiva foram as variáveis que expressaram maior correlação $(0,552)$; Pais-Ribeiro (2012) sustenta que a satisfação com a vida é a dimensão cognitiva do bem-estar subjetivo. Assim como, Fernandes et al. (2007) e Rocha e Porto (2012) que também apontam a satisfação no trabalho como a dimensão cognitiva do bem-estar no trabalho, enquanto os afetos positivos e os afetos negativos configuram uma dimensão afetiva.

Todas as variáveis tiveram correlações expressivas, sendo envolvimento no trabalho e satisfação no trabalho com o resultado mais fraco $(0,193)$ comparado aos outros, mas ainda assim considerável. Considerando o caráter de desempenho do indivíduo como um dos aspectos do envolvimento no trabalho, é possível que alguns trabalhadores estejam envolvidos no trabalho ainda que não tão satisfeitos com ele. Contudo, os dados revelam que mesmo que mais fraco se comparado com as outras variáveis, envolvimento com o trabalho e satisfação no trabalho possuem uma correlação significativa de modo que trabalhadores envolvidos no trabalho também estejam satisfeitos e vice-versa.

\section{CONCLUSÃO}

A partir dos resultados dessa pesquisa e respondendo à questão problema proposta: qual o grau de correlação das variáveis do bem-estar no trabalho (satisfação no

RC: 105620

Disponível em: https://www.nucleodoconhecimento.com.br/psicologia/bem-estar 
trabalho, comprometimento organizacional afetivo, envolvimento no trabalho) com a percepção de bem-estar no contexto de não-trabalho (bem-estar subjetivo); concluise que as variáveis do constructo bem-estar no trabalho correlacionam-se com o bemestar no contexto de não trabalho (bem-estar/felicidade subjetiva) em diferentes graus. Destaca-se a satisfação no trabalho entre esses fatores. O bem-estar no contexto de não trabalho foi considerado a partir da felicidade subjetiva, esta variável está relacionada a um sentimento positivo perante a vida.

Constata-se que para a percepção do bem-estar na vida de maneira geral (felicidade subjetiva) o bem-estar no trabalho, sobretudo, a variável satisfação no trabalho se configura como um fator importante, com correlação de 0,552 indo ao encontro das pesquisas de Diener e Lucas (2000), Keyes; Shimotkin e Ryff (2002), Fernandes et al. (2007) e Pais-Ribeiro (2012); sendo assim, os resultados do presente estudo sugerem correlação significativa $(0,552)$, principalmente, na dimensão cognitiva do bem-estar subjetivo, onde a satisfação com a vida é tida como variável.

Apesar das variáveis envolvimento no trabalho e comprometimento no trabalho apresentarem correlação com a variável felicidade subjetiva, a relação foi mais fraca, respectivamente, 0,214 e 0,287. Devido ao caráter tridimensional da variável comprometimento no trabalho, proposto por Meyer e Allen (1991), Bastos e Rodrigues (2009), Rowe e Bastos (2009) é de interesse a análise através de estudos futuros que considere, de forma separada, as três bases do comprometimento no trabalho (afetiva, normativa e instrumental ou calculativo) com intuito de observar se há diferença significativa na correlação da felicidade subjetiva com cada dimensão da variável comprometimento no trabalho. Compreendendo assim, se a correlação do comprometimento com a felicidade subjetiva se faz, prioritariamente, pelo vínculo afetivo em relação à organização, com o sujeito identificando-se e envolvendo-se com ela (comprometimento a partir da base afetiva), ou se há mais forte correlação quando o comprometimento é experenciado, sobretudo, a partir da dimensão normativa (sentimento de dever), ou ainda, a partir da dimensão instrumental (decorrente do reconhecimento dos custos em deixar a organização). 
O envolvimento no trabalho possui correlação com a satisfação no trabalho, apesar de não ser uma relação alta $(0,193)$, assim como a relação entre a variável satisfação no trabalho com a variável comprometimento organizacional afetivo $(0,247)$. O investimento de tempo e energia por parte do indivíduo pode ser considerado um aspecto característico de um indivíduo envolvido e comprometido com organização, conforme os dados de correlação de 0,504 entre comprometimento afetivo no trabalho e envolvimento no trabalho; isso é possível quando o trabalhador percebe o significado da atividade para si mesmo, bem como, sua capacidade em realizá-la. Apesar disso, as variáveis envolvimento no trabalho e comprometimento organizacional afetivo apresentam um grau mais fraco de correlação com o bem-estar subjetivo (felicidade subjetiva) se comparado à variável satisfação no trabalho, respectivamente, 0,214 e 0,287 .

O objetivo do trabalho foi analisar o bem-estar no contexto do trabalho a partir de seu caráter superordenado, composto pelas variáveis: satisfação no trabalho, envolvimento no trabalho e comprometimento organizacional afetivo; e o bem-estar no contexto de não-trabalho (bem estar subjetivo) através da variável felicidade subjetiva. Entretanto, ainda que o estudo tenha alcançado o objetivo proposto e tenha oferecido contribuições ao campo do bem-estar no trabalho, é válido o desenvolvimento de pesquisas futuras específicas do construto do bem-estar no trabalho e no não-trabalho, haja vista a escassez de estudos como este.

O impacto das atividades laborais no cotidiano do indivíduo e a diminuição da barreira entre trabalho e vida pessoal apresentam a complexidade desse constructo. Além disso, as constantes transformações nesse cenário revelam a importância do acompanhamento dos estudos sobre o bem-estar no trabalho e fora dele nesse processo histórico-social. 


\section{REFERÊNCIAS}

ARAÚJO, P. M.; OLIVEIRA, Áurea de Fátima. Bem-Estar no trabalho: impacto das percepções dos valores organizacionais e da confiança do empregado na organização. Horizonte Científico, v.2, p.1-26, out. 2008.

BASTOS, Antônio Virgílio Bittencourt. et al. Comprometimento no trabalho: Fundamentos para a gestão de pessoas. In: BORGES, Lívia de Oliveira.; MOURÃO, Luciana (Orgs.), O trabalho e as organizações: Atuações a partir da psicologia. Porto Alegre: Artmed, 2013, p. 279-310.

BASTOS, Antônio Virgílio Bittencourt.; RIBEIRO, José Adauto. Comprometimento e justiça organizacional: Um estudo de suas relações com recompensas assimétricas. Psicologia Ciência e profissão, v.30, p.4 - 21. 2010. Disponível em: <http://www.scielo.br/pdf/pcp/v30n1/v30n1a02.pdf>. Acesso em: 06 ago. 2021.

BASTOS, Antônio Virgílio Bittencourt; RODRIGUES, Ana Carolina de Aguiar. Problemas conceituais e empíricos na pesquisa sobre comprometimento organizacional: uma análise crítica do modelo tridimensional de J. Meyer e N. Allen. Revista Psicologia, Organizações e Trabalho, v.10 n.2, p.129 - 144, dez. 2010.

Disponível em: <http://pepsic.bvsalud.org/scielo.php?script=sci_arttext\&pid=S198466572010000200010>.Acesso em 18 dez. 2021.

CARVALHO, Patrícia et al. Comprometimento afetivo, de continuação e entrincheiramento organizacional: estabelecendo limites conceituais e empíricos. Revista Psicologia: teoria e prática, v.13, n.2, p.127-141, 2011. Disponível em: <http://pepsic.bvsalud.org/pdf/ptp/v13n2/v13n2a10.pdf>. Acesso em 06 ago. 2021.

CAVALCANTE, Marcileide Muniz.; SIQUEIRA, Marlene Maria Matias.; KUNIYOSHI, Márcio Shoiti. Engajamento, bem-estar no trabalho e capital psicológico: um estudo com profissionais da área de gestão de pessoas. Revista Pensamento e Realidade, 
v.29,

n.4,

p.42

64, 2014.

Disponível

em:

https://revistas.pucsp.br/pensamentorealidade/article/view/22391>. Acesso em 06 ago. 2021.

COVACS, Jorge Miguel Luiz Macedo de. Bem-estar no trabalho: o impacto dos valores organizacionais, percepção de suporte organizacional e percepções de justiça. 2006. 117f. Tese (Mestrado) - Programa de Pós Graduação em psicologia da saúde, Universidade Metodista de São Paulo, São Bernardo do Campo, 2006. Disponível em: http://tede.metodista.br/jspui/bitstream/tede/1384/1/JORGE\%20MIGUEL\%20L\%20M \%20COVCS.pdf>. Acesso em: 06 ago. 2021.

CSIKSZENTMIHALYI, Mihaly. Gestão qualificada: a conexão entre felicidade e negócio. (R. Rubenich, Trad.). Porto Alegre: Bookman., 2004.

DESSEN, Marina Campos; PAZ, da Maria das Graças Torres. Validação do instrumento de indicadores de Bem- Estar pessoal nas organizações. Psicologia em Estudo, v.15, n.2, p.409 - 418, abr./jun.2010. Disponível em: <http://www.scielo.br/pdf/pe/v15n2/a20v15n2>. Acesso em: 07 ago. 2021.

DIENER, Ed.; LUCAS, Richard. E. Subjetive emotional well-being. In: LEWIS, Michael.; HAVILAND-JONES, Jeannette M. Handbook of Emotions. New York: Guilford, 2000, p. 325-337.

DIENER, Ed.; LUCAS, Richard E.; SCOLLON Christie Napa. The evolving concept of subjective well-being: the multifaceted nature of happiness. In: COSTA, P.; SIEGLER, Ilene C. Advances in Cell Aging and Gerontology, v.15, p.187- 220, 2004.

FERNANDES, Helenita de Araújo et al. O bem-estar no trabalho e a predição de exaustão emocional. In: Encontro Nacional da Associação Nacional de Programas de Pós Graduação, 31., 2007. Disponível em: 
$<$ http://www.congressousp.fipecafi.org/web/artigos92009/467.pdf>. Acesso em 07 ago. 2021.

KEYES, Corey Lee M.; RYFF, Carol Diane. The structure of psychological well-being revisited. Journal of Personality and Social Psychology, v.69, n.4, p.719 - 72, 1995. Diponível em:http://midus.wisc.edu/findings/pdfs/830.pdf. Acesso em: 07 ago. 2021.

KEYES, Corey Lee M.; SHMOTKI, Dov.; RYFF, Carol Diane. Optimizing well being: The empirical encounter of two traditions. Journal of Personality and Social Psychology, v.82, n.6, p.1007-1022, 2002. Disponível em: $<$ http://citeseerx.ist.psu.edu/viewdoc/download?doi=10.1.1.371.9869\&rep=rep1\&type $=$ pdf $>$. Acesso em: 07 ago. 2021.

LEAL, Aline Luisa Andrade de. Bem- Estar no trabalho entre docentes universitários: estudo de caso em uma IES pública. 2008. 92f. Tese (Mestrado) Escola de Administração, Universidade Federal da Bahia, Salvador, 2008. Disponível em: < https://repositorio.ufba.br/ri/bitstream/ri/8054/1/AAAAAAAAAAA.pdf>. Acesso em: 06 ago. 2021.

LYBOMIRSKY, Sonja.; LEPPER, Heidi S. A measure of subjective happiness: preliminary reliability and construct validation. Social Indicators Research, v.46, n.2, p.137-

155,1999.Disponívelem:<https://escholarship.org/content/qt2185n8gb/qt2185n8gb.pd f?t=oruxh2>. Acesso em: 06 ago. 2021.

MACHADO, Wagner Lara de. Adaptação da escala de Bem-Estar Psicológico. 2010. 60f. Tese (Mestrado) - Instituto de Psicologia, Universidade Federal do Rio Grande do Sul, Rio Grande do Sul, 2010. Disponível em: <https://www.lume.ufrgs.br/bitstream/handle/10183/29716/000778689.pdf?...1>. Acesso em: 06 ago. 2021. 
MARTINEZ, Maria Carmen; PARAGUAY, Ana Isabel Bruzzi Bezerra Paraguay. Satisfação e saúde no trabalho - aspectos conceituais e metodológicos. Cadernos de Psicologia Social do Trabalho, v.6, 59 - 78. 2003. Disponível em:< http://www.revistas.usp.br/cpst/article/view/25851/27583>. Acesso em 18 dez. 2021.

MARTINS, Vanessa.; COSTA, Luciano Venelli.; SIQUEIRA, Marlene Maria Matias. O impacto do comprometimento afetivo e do engajamento no trabalho sobre os comportamentos de cidadania organizacional. Revista de Administração, Contabilidade e Economia da FUNDACE, v.6, n.2, p.1 - 12, dez. 2015. Disponível em: < https://www.fundace.org.br/revistaracef/index.php/racef/article/view/327/75>. Acesso em: 06 ago. 2021.

MEDEIROS, Carlos Alberto Freire. Comprometimento organizacional: um estudo de suas relações com características organizacionais e desempenho nas empresas hoteleiras. 2005. 166f. Tese (Doutorado) - Faculdade de Economia, Administrativa e Contabilidade, Universidade de São Paulo, São Paulo, 2003. Disponível em:< https://www.teses.usp.br/teses/disponiveis/12/12139/tde-05042004-

105813/publico/Tese_Doutorado_Medeiros_2003.pdf>. Acesso em: 06 ago. 2021.

MEDEIROS, Carlos Alberto Freire et al. Comprometimento Organizacional: o estado da arte da pesquisa no Brasil. Revista de Administração Contemporânea, v.7, n.4, p.187 - 209, 2003. Disponível em: < http://www.spell.org.br/documentos/ver/17372/comprometimento-organizacional--oestado-da-arte-da-pesquisa-no-brasil>. Acesso em: 06 ago. 2021.

MUCHINSKY, Paul M. Psicologia Organizacional. (R. G. Bahr, Trad.) São Paulo: Pioneira Thomson Learning., 2004.

PAIS-RIBEIRO, José Luis. Validação transcultural da escala de felicidade subjetiva de Lyubomirsky e Lepper. Psicologia, Saúde e Doenças, v.13, n.2, p.157 - 168, 2012. Disponível em: < http://repositorio.ispa.pt/bitstream/10400.12/2488/1/PSD_13_157168.pdf>. Acesso em: 06 ago. 2021. 
PASCHOAL, Tatiane.; TORRES, Cláudio Vaz.; PORTO, Juliana Barreiros. Felicidade no trabalho: Relações com suporte organizacional e suporte social. Revista Administração Contemporânea, v.14, n.6, p. 1054 -1072, nov./dez. 2010. Disponível em:< Recuperado de http://www.scielo.br/pdf/rac/v14n6/v14n6a05.pdf >. Acesso em: 06 ago. 2021.

ROCHA Fábio Sobrinho.; PORTO, Juliana Barreiros. Bem estar no trabalho: Um estudo sobre suas relações com clima social, coping e variáveis demográficas. Revista de Administração Contemporânea. v.16, n.2, p. 253 - 270. Mar./abr. 2012. Disponível em: <http://www.scielo.br/pdf/rac/v16n2/v16n2a06.pdf>. Acesso em: 06 ago. 2021.

ROWE, Diva Ester Okazaki.; BASTOS, Antonio Virgílio Bittencourt. Comprometimento organizacional e desempenho acadêmico: um estudo com docentes do ensino superior brasileiro. Encontro Nacional da Associação Nacional de Programas de Pós- Graduação, 33., 2009, São Paulo. Disponível em:<http://www.anpad.org.br/diversos/down_zips/45/EOR1133.pdf>.Acesso em 07 ago. 2021.

SCORSOLINI-COMIN, Fabio.; DOS SANTOS, Manuel Antonio. Satisfação com a vida e satisfação diádica: correlações entre construtos de bem-estar. Psico-USF. v.15, n.2, p.249 - 256, maio/ago. 2010. Disponível em: < https://www.redalyc.org/pdf/4010/401036080012.pdf>. Acesso em: 06 ago. 2021.

SIQUEIRA, Marlene Maria Matias. Antecedentes de comportamentos de cidadania organizacional: a análise de um modelo pós-cognitivo. 1995. Tese (Doutorado) Programa de Pós Graduação em Psicologia, Universidade de Brasília, Distrito Federal.

SIQUEIRA, Marlene Maria Matias (Org.). Medidas do comportamento Organizacional: ferramentas e diagnósticos e de gestão. Porto Alegre: Artmed, 2008. 
Novas Medidas do comportamento Organizacional: ferramentas e diagnósticos e de gestão. Porto Alegre: Artmed, 2014.

SIQUEIRA, Marlene Maria Matias.; GOMIDE, Sinésio Júnior. Vínculos do indivíduo com o trabalho e com a organização. In: BASTOS, Antonio Virgílio Bittencourt.; ZANELLI, José Carlos.; BORGES-ANDRADE, Jairo Eduardo (Orgs). Psicologia, organização e trabalho no Brasil, 2. ed. Porto Alegre: Artmed, 2004, p.317-348.

SIQUEIRA, Marlene Maria Matias; PADOVAM, Valquiria Aparecida Rossi. Bases teóricas de bem-estar subjetivo, bem estar psicológico e bem-estar no trabalho. Psicologia: Teoria e Pesquisa, v.24, n.2, p.201 - 209, jun. 2008. Disponível em:< http://www.scielo.br/scielo.php?pid=S0102-

37722008000200010\&script=sci_abstract\&tlng=pt>. Acesso em: 06 ago. 2021.

STEUER, Ruth Silvia; DALLARI, Sueli Gadolfi. Satisfação no trabalho, conflito e ambiguidade de papéis: estudo junto às enfermeiras de Maternidade Escola do Município de São Paulo. 1989. Tese (Mestrado) — Universidade de São Paulo, São Paulo, 1989.

TRALDI, Maria Teodora Farias.; DEMO, Gisela. Comprometimento, bem-estar e satisfação dos professores de administração de uma universidade federal. Revista Eletrônica de Administração, v.72, n.2, p.290 - 316, ago.2012. Disponível em:<http://www.scielo.br/scielo.php?script=sci_arttext\&pid=S1413-

$23112012000200001>$. Acesso em: 07 ago. 2021.

VALENTE, Luis Eduardo. Bem-estar subjetivo e bem-estar no trabalho em profissionais de educação física. 2007. 58f. Tese (Mestrado) — Programa de Pós Graduação em Psicologia, Universidade Metodista de São Paulo, São Bernardo do Campo, 2007.

Disponívelem:<http://tede.metodista.br/jspui/bitstream/tede/1397/1/LUIS\%20EDUAR DO\%20VALENTE.pdf>. Acesso em: 06 ago. 2021. 
Enviado: Agosto, 2021.

Aprovado: Janeiro, 2022.

RC: 105620

Disponível em: https://www.nucleodoconhecimento.com.br/psicologia/bem-estar 